\title{
EXPIRATION DATE DETERMINATION OF THERMALLY PROCESSED POTATO MAIN COURSE IN RETORT PACKAGING
}

\author{
Aija Ruzaike ${ }^{1 *}$, Sandra Muizniece-Brasava ${ }^{1}$, Kaspars Kovalenko $^{2}$ \\ I* Department of Food Technology, Faculty of Food Technology, Latvia University of Agriculture, Rigas iela 22, Jelgava, Latvia, \\ *e-mail:aija.ruzaike@gmail.com \\ ${ }^{2}$ Institute of Food and Environmental Hygiene, Faculty of Veterinary Medicine, Latvia University of Agriculture, K. Helmana iela 8 , \\ Jelgava, Latvia
}

\begin{abstract}
Consumer interest in health and wellness prompted the food industry to develop alternative processing technological solutions for preserving low-acid shelf-stable foods. The aim of this study was to assess the expiration date and quality determining factors of potato main course in retort packaging. The study was conducted at the Faculty of Food Technology and the Faculty of Veterinary Medicine, Latvia University of Agriculture. Four different potato main course types - with amaranth (66\% potato, 33\% amaranth, $1 \%$ spices and salt), quinoa (66\% potato, $33 \%$ quinoa, $1 \%$ spices and salt), bulgur (66\% potato, $33 \%$ bulgur, $1 \%$ spices and salt) and chicken fillet $(49.5 \%$ chicken fillet, potato $49.5 \%, 1 \%$ spices and salt) - were investigated. All main courses were packaged in three different packaging materials, two-layer laminated transparent polyamide/polyethylene film (PA/PE), and four-layer opaque, laminated polyethylene terephthalate / aluminium / polyamide / polypropylene (PET/ALU/PA/PP) packaging. During the 22-month storage, mesophilic aerobic and facultative anaerobic microorganisms (TPC), $\mathrm{pH}$ and colour $\mathrm{L}^{*} \mathrm{a}^{*} \mathrm{~b}^{*}$ changes in all potato main courses were tested once every month. The results demonstrated that the expiration date of potato main course in PA/PE packaging is 8 months, while the expiration date of potato main course in PET/ALU/PA/PP packaging reaches 22 months.
\end{abstract}

Keywords: potato main course, expiration date, retort packaging.

\section{Introduction}

In the recent years, the growth in the sector of prepared meals has been observed in the food industry (Calderón et al., 2010; Olsen et al, 2010; Kanatt et al., 2013; Regueiro, Wenzl, 2015; Stratakos et al., 2015; Hanssen et al., 2015). Prepared meals can be defined as pre-prepared, chilled or frozen foods, which do not need additional ingredients and require minimum preparation before consumption (Mahon et al., 2006; Regueiro, Wenzl, 2015; Remnant, Adam, 2015). These products have gained considerable popularity because of the lack of time for most consumers (Calderón et al., 2010; Stratakos et al., 2015). The main reason for choosing prepared meals is the convenient use and the low cost compared to home-cooked meals (Remnant, Adam, 2015). Consumers are becoming more demanding for high quality food products with excellent organoleptic and health neutral properties (Moronta et al., 2016).

Canned products in packaging of convenient shape with shelf-life over one year are an important component of the diet for the majority of the population in the developed counties (Patras et al., 2009).

Thermal processing, specifically in retort packaging, has been used as a common preservation technique in food industry for shelf stable low-acid foods (Byun et al., 2010). The United States Food and Drug Administration (FDA) has classified foods in the federal register (21 CFR Part 114) as follows: (i) acid foods, (ii) acidified foods and (iii) low acid foods. Acid foods are those that have a natural $\mathrm{pH}$ of 4.6 or below. Thus, a pH of 4.6 represents a demarcating line between low and high acid foods. During thermal processing of low acid foods $(\mathrm{pH} \geq 4.6)$, attention is given to $C$. botulinum - the highly heat resistant, rodshaped, spore former that thrives comfortably under anaerobic conditions to produce the botulism toxin (Awuah et al., 2007). The aim of sterilization is to ensure that all cold points (worst case processing scenario) in the food product receive thermal treatment capable of reducing the Clostridium botulinum load for $12-\log$ cycles. The time required to reach this final microbial load is known as $12 D$, where $D$ is the treatment time required to reduce the number of microorganisms to the tenth. These processing conditions allow the ability to ensure shelf stable low-acid products (Patras et al., 2009; BarbosaCánovasa et al., 2014). Processors of low-acid canned foods must have an effective and efficient control system over the retort sterilization process to avoid unexpected process deviations that would question the lethality of the resulting process (Simpsona et al., 2007). Commercial retort processing ensures a reduction or inactivation of spore-forming microorganisms sufficient to guarantee commercial sterility (Byun et al., 2010).

Retorting is a method of preserving food by heating it in hermetically sealed containers like cans, glass jars, semi-rigid thermoformed containers and retortable pouches (Bindu et al., 2012; BarbosaCánovasa et al., 2014). The retort pouch is a 3-ply multi-layer flexible packaging consisting mainly of polypropylene, aluminium foil and polyester. Pouches can withstand sterilization temperatures up to $130{ }^{\circ} \mathrm{C}$. Retortable pouches allow more rapid heat transfer than cylindrical metals and glass containers of equivalent volume. Commodities that have been packed in thin profile pouches include meat curries, stews, highquality meat products, frankfurters, ready meals, gourmet sauces, corn, green beans, sliced or diced carrots (Awuah et al., 2007).

The choice of packaging is essential for products intended for long-term storage, as the storage time and temperature significantly affect the appearance, aroma, 
flavour and structure of the product (Clark et al., 2002). Packaging plays an important role in maintaining food quality, because each package is an important part of the food that isolates the product from adverse external environment factors (Ahvenainen, 2003; Pardo, Zufía, 2012). Traditionally, canned food products have not been perceived by consumers to have high quality, however, the emphasis is placed on shelf stable retort pouch products of higher quality. The retort pouch minimizes the thermal damage to nutrient, sensory, and other food quality characteristics due to quicker heating based on the thinner package profile when compared to metal cans (Awuah et al., 2007; Byun et al., 2010). The colour of processed foods plays a role by influencing consumer acceptability. Natural occurring pigments in foods are susceptible to changes or degradation from heat. Chlorophylls (in photosynthetic tissues), anthocyanins (the red and blue hues associated with many fruits and vegetables), carotenoids (found in fruits, dairy products, egg, fish and vegetables) and betanins (present in red beet roots) form the major classes of pigments. Anthocyanins are converted to brown pigments by heat. While traditional retorting can affect some of these pigments due to prolonged heat exposure, high-temperature short-time operations can be expected to minimize these changes considerably (Awuah et al., 2007).

\section{Materials and Methods}

Experiments were carried out at the laboratories of the Faculty of Food Technology and the Faculty of Veterinary Medicine, Latvia University of Agriculture. Microbiological parameters were determined at the Molecular Biology and Microbiology Research Laboratory, Latvia University of Agriculture and the laboratories of Institute of Food and Environmental Hygiene, Faculty of Veterinary Medicine. Prepared meal samples were made and subjected to physical analysis $\left(\mathrm{pH}\right.$, colour components $\left.\mathrm{L}^{*} \mathrm{a}^{*} \mathrm{~b}^{*}\right)$ at the Packaging Material Properties Research Laboratory, Department of Food Technology. Four different types of potato main course samples and control sample (potatoes) were prepared for this study: potatoes with amaranth (Amaranthus L.) $(66 \%$ potato, $33 \%$ amaranth, $1 \%$ spices and salt), potatoes with quinoa (Chenopodium quinoa Wild.) (66\% potato, $33 \%$ quinoa, $1 \%$ spices and salt), potatoes with bulgur (Triticum durum Desf.) (66\% potato, 33\% bulgur, $1 \%$ spices and salt) and potatoes with chicken fillet (49.5\% chicken fillet, $49.5 \%$ potato, $1 \%$ spices and salt) (Fig. 1).

Peeled potatoes were cut by Robot Coupe vegetable preparation machine CL50 in equal-sized cubes $(10 \times 10 \mathrm{~mm})$. Cut potatoes were mixed with chicken fillet, which was cut into medium-sized pieces, or amaranth, quinoa, or bulgur, then $1 \%$ spices and salt was added to each sample. After mixing, products $(300 \pm 10 \mathrm{~g})$ were filled in $200 \times 250 \mathrm{~mm}$ sized laminated pouches. Three different packaging materials suitable for thermal treatment were used: two-layer PA/PE (polyamide / polyethylene) laminated packaging material with $80 \mu \mathrm{m}$ thickness, PET / ALU / PA / PP (polyethylene terephthalate / aluminium / polyamide / polypropylene) packaging material with aluminium layer, $\quad 110 \mu \mathrm{m}$ thickness and three-layer $\mathrm{PA} / \mathrm{EVOH} / \mathrm{PE}$ (polyamide / ethylene vinyl alcohol / polyethylene) laminated packaging material with UV barrier properties and $80 \mu \mathrm{m}$ thickness.

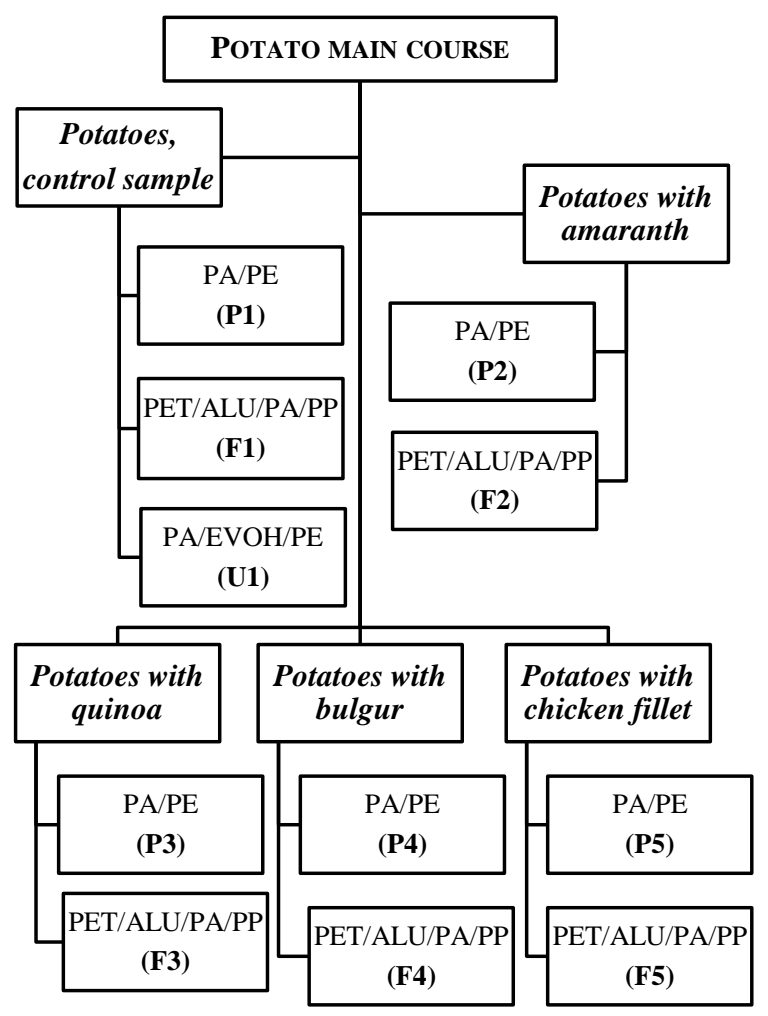

Figure 1. Potato main courses samples

After filling, pouches of potato main course were hermetically sealed using chamber type vacuum packaging machine Multivac C350; hermetic sealing mode - vacuum, 20 mbar, sealing time for PA / PE and $\mathrm{PA} / \mathrm{EVOH}$ / PE packaging - 3.8 seconds, sealing time for PET / ALU / PA / PP packaging - 5 seconds. Vacuum sealed pouches were then thermally treated in a pilot autoclave HST 50/100, ZIRBUS Technology $\mathrm{GmbH}$ (Germany). Sterilization was carried out at $120 \pm 2{ }^{\circ} \mathrm{C}$ for $10 \mathrm{~min}$, the cooling temperature was $20 \pm 2{ }^{\circ} \mathrm{C}$ in product. After thermal treatment, sterilized products were stored at $20 \pm 2{ }^{\circ} \mathrm{C}$ for 22 months. Physical analysis and microbiological parameters were determined on the production day and once every month during 22-month storage.

Microbiological parameters

Aerobic and facultative anaerobic, mesophilic bacteria (hereafter referred to as TPC, total plate count) were determined according to the standard EN ISO 4833: 2003 "Microbiology of food and animal feeding stuffs - Horizontal method for the enumeration of microorganisms - Colony-count technique at 30 degrees C" on Plate Count Agar (PCA) medium. 
Determination of $\mathrm{pH}$

$\mathrm{pH}$ of potato products was determined using $\mathrm{pH}$-meter JENWAY 3510 with electrodes JENWAY $3 \mathrm{~mol} / \mathrm{KCl}$ (standard method ISO 1842:1991).

\section{Colour analysis}

Colour of potato product of samples was determined using Colour Tec PCM / PSM with CIE L*a*b* colour system. Measurements were completed in tenfold repetition for each sample for more precise calculations of the mean value and standard deviation. Measurements were recorded using data program Colour Soft QCW. Total colour difference $\left(\Delta \mathrm{E}^{*}\right)$ of potato products between the initial value and after storage was calculated using the following equation 1 :

$$
\Delta E^{*}=\sqrt{\left(L^{*}-L_{0}^{*}\right)^{2}+\left(a^{*}-a_{0}^{*}\right)^{2}+\left(b^{*}-b_{0}^{*}\right)^{2}}
$$

where

$\Delta \mathrm{E}^{*}$ - total colour difference of the product during storage,

$\mathrm{L}^{*}$ - colour intensity value at the final product storage day,

$\mathrm{L}_{0} *$ - colour intensity value at day 0 ,

$a^{*}$ - value of colour component green - red at the final product storage day,

$\mathrm{a} 0^{*}$ - value of colour component green - red at day 0 ,

$b^{*}$ - value of colour component blue - yellow at the final product storage day,

$\mathrm{b}_{0} *$ - value of colour component blue - yellow at day 0 .

Data analysis

The obtained data were processed using SPSS software package 16.0; differences among results were considered significant if $\mathrm{p}$-value $<0.05$. One way analysis of variance (ANOVA) and Tukey's test were used to interpret the results.

\section{Results and Discussion}

Foodborne illnesses are still at a very high level in Europe. Plant based raw materials are mainly contaminated with the undesirable microflora during growth, harvesting, primary processing, manufacturing, as well as during distribution and transport (Birmpa et al., 2013). Food producers and processors must control products during all of the processing stages in order to prevent or reduce the contamination of food to acceptable levels, therefore, the knowledge of food safety and hygiene are necessary to protect consumers from food poisoning caused by food infections (Smigic et al., 2016; Gomess et al., 2014). Potato main courses in PA / PE packaging (samples P1, P2, P3, P4, P5), PET / ALU / PA / PP packaging (samples F1, F2, F3, F4, F5) and PA / EVOH / PE packaging (sample U1) were tested for the presence of aerobic and facultative anaerobic microorganisms (TPC) immediately after the heat treatment and during 22-month storage at $20 \pm 2{ }^{\circ} \mathrm{C}$.

The results showed that TPC in potato main course packed in PA / PE and PA / EVOH / PE immediately after heat treatment and during 8-month storage did not exceed $<10 \mathrm{CFU} \mathrm{g}^{-1}$. Microbiological testing of these samples in $\mathrm{PA} / \mathrm{PE}(\mathrm{P} 1, \mathrm{P} 2, \mathrm{P} 3, \mathrm{P} 4, \mathrm{P} 5)$ and
PA / EVOH / PE (U1) packaging was not carried out after 8-month storage, because the sensory characteristics (taste, colour, structure) did not meet the desired product quality requirements. It was concluded that the shelf-life of potato main course in the abovementioned packaging materials is 8 months. By contrast, potato main course in PET / ALU / PA / PP (F1, F2, F3, F4, F5) packaging demonstrated microbial contamination below $10 \mathrm{CFU} \mathrm{g}{ }^{-1}$ immediately after heat treatment and during 22-month storage, without significant changes in organoleptic characteristics.

Based on the results of microbiological testing, it can be concluded that the potato main course in PA / PE and $\mathrm{PA} / \mathrm{EVOH} / \mathrm{PE}$ packaging is safe for human consumption till 8 -month storage at $20 \pm 2{ }^{\circ} \mathrm{C}$ room temperature, whereas potato main course in PET / ALU / PA / PE packaging is safe for human consumption after 22 -month storage at $20 \pm 2{ }^{\circ} \mathrm{C}$ room temperature.

$\mathrm{pH}$ value is the measurement of acid and alkali ratio. Environment $\mathrm{pH}$ is one of the key factors in determining which microorganisms can grow in the product. Microorganisms which cause food infections typically have an optimum around neutral $\mathrm{pH}-6$ to 7 . The characteristic $\mathrm{pH}$ for vegetables is 4.2 to 6.5 . $\mathrm{pH}$ of fresh potatoes ranges from 5.4 to 5.8 (Suryawanshi, 2008). It should be taken into account that the bacterial resistance to treatment will be different with various pH of products (Garcia-Segovia et al., 2007).

$\mathrm{pH}$ value of potato main courses in PA / PE (P1, P2, P3, P4, P5) and PA / EVOH / PE (U1) packaging during

8-month storage is shown in Fig. 2, while $\mathrm{pH}$ of potato meals in PET / ALU / PA /PP (F1; F2; F3; F4; F5) packaging during 22-month storage at $20 \pm 2{ }^{\circ} \mathrm{C}$ is shown in Fig. 3.

$\mathrm{pH}$ dynamics of potato main course in PA/PE and $\mathrm{PA} / \mathrm{EVOH} / \mathrm{PE}$ packaging showed that none of the samples had significant changes of $\mathrm{pH}$ value $(\mathrm{p}>0.05)$ during 8-month storage. Control sample in different packaging materials - P1 (packed in PA/PE) and U1 (packed in PA/EVOH/PE) - had insignificant changes in $\mathrm{pH}$ dynamics during storage. The initial $\mathrm{pH}$ of sample $\mathrm{P} 1$ was $5.77 \pm 0.01$, while the initial $\mathrm{pH}$ of sample U1 was $5.75 \pm 0.01$. After an 8 -month period, $\mathrm{pH}$ of samples $\mathrm{P} 1$ and $\mathrm{U} 1$ was $5.71 \pm 0.01$ and $5.7 \pm 0.01$, respectively. For the other samples with different potato main course types, the highest initial $\mathrm{pH}$ value was observed for potatoes with chicken (P5) $6.07 \pm 0.01$, however, during 8-month storage it decreased to $\mathrm{pH} 5.96 \pm 0.01$ which was not considered significant $(\mathrm{p}>0.05)$. Similar $\mathrm{pH}$ changes were observed in sample P4 - potatoes with bulgur. Throughout the storage period the least changes of $\mathrm{pH}$ were observed in sample U1 (potatoes, control sample) packed in PA / EVOH / PE, a total of 0.05 units.

The results of $\mathrm{pH}$ dynamics of potato main courses in PET / ALU / PA / PP packaging during 22-month storage at $20 \pm 2{ }^{\circ} \mathrm{C}$ showed insignificant changes ( $>0.05$ ). 


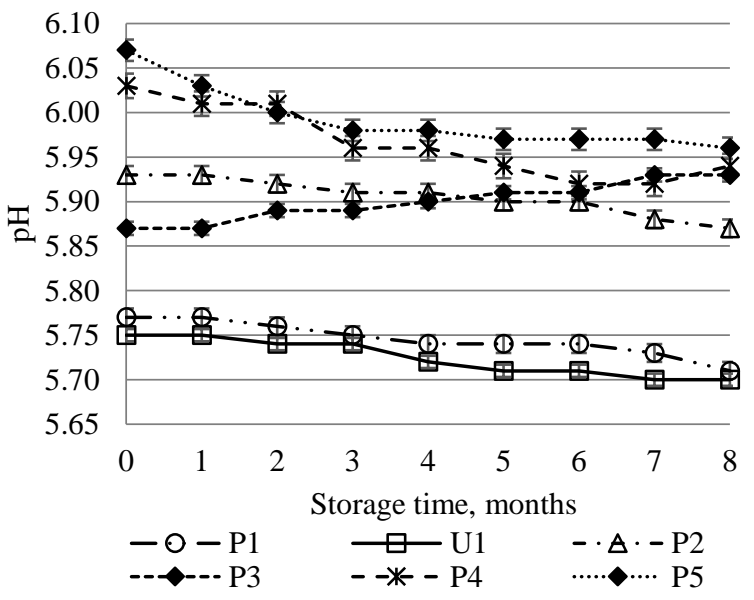

Figure 2. Changes in $\mathrm{pH}$ of potato main course in PA / PE (P1, P2, P3, P4, P5) and PA / EVOH / PE

(U1) packaging during 8-month storage

P1 - control sample in PE / PA packaging, U1 - control sample in PA / EVOH / PE packaging, P2 - potatoes with amaranth in PE / PA packaging, P3 - potatoes with quinoa in PE / PA packaging, $\mathrm{P} 4$ - potatoes with bulgur in PE / PA packaging, P5 - potatoes with chicken fillet in $\mathrm{PE} / \mathrm{PA}$ packaging

The comparison of potato main courses in $\mathrm{PA} / \mathrm{PE}$ packaging (8-month storage at $20 \pm 2{ }^{\circ} \mathrm{C}$ ) with samples in PET / ALU / PA / PP packaging (22-month storage at $20 \pm 2{ }^{\circ} \mathrm{C}$ ) indicates that $\mathrm{pH}$ value of samples did not depend on the type of packaging.

The initial $\mathrm{pH}$ of potato main course control sample $\mathrm{P} 1$ was $5.77 \pm 0.01$, and after 8 -month storage it decreased to $5.71 \pm 0.01$ (Fig. 2), whereas the initial $\mathrm{pH}$ of potato main course control sample F1 was $5.79 \pm 0.01$ and after

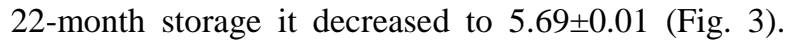
Such comparison of potato main course with quinoa in PA / PE packaging (P3) and PET / ALU / PA / PP packaging $(\mathrm{F} 3)$ showed that initial $\mathrm{pH}$ values were $5.87 \pm 0.01$ and $5.90 \pm 0.01$, respectively, but after 8-month storage - 5.93 \pm 0.01 (P3) and 22-month storage $-5.98 \pm 0.01$ (F3). Throughout the storage period the least changes of $\mathrm{pH}$ were observed in sample F3 (potatoes with quinoa) packed in PET / ALU / PA / PP, a total of 0.08 units, whereas sample F2 (potatoes with amaranth) in PET / ALU / PA / PP packaging showed the greatest $\mathrm{pH}$ changes - a total of 0.15 units which was considered significant $(\mathrm{p}<0.05)$.

Colour changes can be observed in foods during storage due to the exposure to fluorescent light. Light promotes the discoloration of products, the formation of unwanted odours, and it reduces the shelf life in spite of the compliance to the temperature regimes (Murcia et al., 2003). Consequently, appropriate food packaging materials and processing technology can significantly extend the shelf life of products.

The total colour changes of potato main course during storage were characterised by the total colour difference $\Delta \mathrm{E}^{*}$, which was calculated from $\mathrm{L}^{*}, \mathrm{a}^{*}$ and $b^{*}$ values. The total colour difference of all potato main course types in $\mathrm{PA} / \mathrm{PE}, \mathrm{PA} / \mathrm{EVOH} / \mathrm{PE}$ and $\mathrm{PET} / \mathrm{ALU} / \mathrm{PA} / \mathrm{PP}$ packaging are summarised in

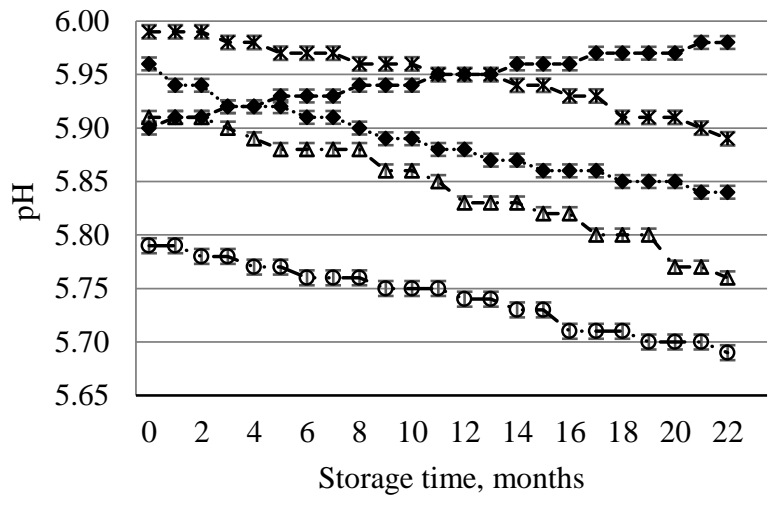

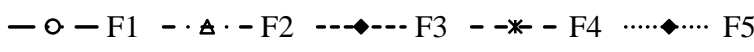

Figure 3. Changes in $\mathrm{pH}$ of potato main course in PET / ALU / PA / PP (F1, F2, F3, F4, F5)

packaging during 22-month storage

F1 - control sample in PET / ALU / PA / PP packaging, F2 - potatoes with amaranth in PET / ALU / PA / PP packaging, F3 - potatoes with quinoa in PET / ALU / $\mathrm{PA} / \mathrm{PP}$ packaging, F4 - potatoes with bulgur in PET / ALU / PA / PP packaging, F5 - potatoes with chicken fillet in PET / ALU / PA / PP packaging

Figure 4. The results demonstrate that potato main courses packed in PA / PE (P1, P2, P3, P4, P5) had significant colour changes $(\mathrm{p}<0.05)$ after 8-month storage, which considerably influenced the visual appearance of the product and cannot be considered appropriate for further research, as colour is one of the main factors which the consumer perceives as the quality indicator of the product (Suryawanshi, 2008).

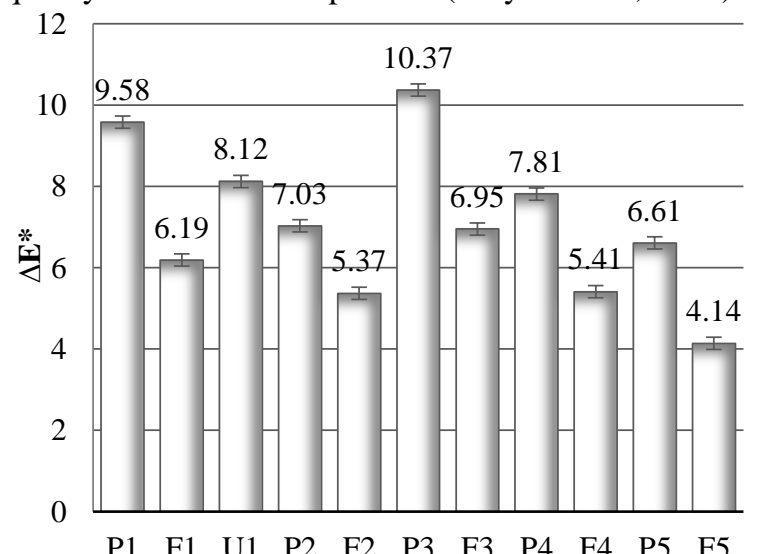

Figure 4. The total colour difference $\Delta \mathrm{E}^{*}$ of potato main course after 8-month (P1, U1, P2, P3, P4, P5)

and after 22-month (F1, F2, F3, F4, F5) storage

P1 - control sample in PE / PA packaging, F1 - control sample in PET / ALU / PA / PP packaging, U1 - control sample in PA / EVOH / PE packaging, P2 - potatoes with amaranth in PE/PA packaging, F2 - potatoes with amaranth in PET / ALU / PA / PP packaging, P3 - potatoes with quinoa in PE/PA packaging, F3 - potatoes with quinoa in PET / ALU / PA / PP packaging, P4 - potatoes with bulgur in PE / PA packaging, F4 - potatoes with bulgur in PET / ALU / PA / PP packaging, P5 - potatoes with chicken fillet in PE/PA packaging, F5 - potatoes with chicken fillet in PET / ALU / PA / PP packaging 
Evaluating the packaging material $\mathrm{PE} / \mathrm{EVOH} / \mathrm{PE}$ with UV protective layer, it can be concluded that the overall colour difference $\Delta \mathrm{E}^{*}$ for sample U1 was not significantly different $(p>0.05)$ compared to potato main course in PA / PE packaging (sample P1). Thus, the total colour difference was studied further only for potato courses in PET / ALU / PA / PP packaging (samples F1, F2, F3, F4, F5) during the storage period of 8 to 22 months.

Figure 4 shows the total colour difference $\Delta \mathrm{E}^{*}$ for all types of potato main courses and all three packaging materials to illustrate the variation of colour difference and demonstrate the importance of packaging materials in maintaining product quality. Potato main course sample P1 (potatoes - control sample) had the total colour difference of $\Delta \mathrm{E}^{*} 9.58$ units after 8-month storage, which is about 1.5 times higher than for sample F1 (potatoes - control sample) that was stored for

14-month longer period. The highest total colour difference was observed for potato main course P3 potatoes with quinoa in PA/PE packaging, compiling up to $\Delta \mathrm{E}^{*} 10.37$ units, which was 1.49 times higher than for potatoes with quinoa in PET / ALU / PA / PP packaging (F3) after 22-month storage.

These results can be explained by the difference in light transmission and barrier properties of various packaging materials, which have a significant role in maintaining the product quality during prolonged storage.

\section{Conclusions}

The most suitable packaging material for prepared ready-to-eat potato main course was PET / ALU / PA / PP, as it was able to ensure consistent product quality during 22-month storage at $20 \pm 2{ }^{\circ} \mathrm{C}$ temperature. Potato main course packed in $\mathrm{PA} / \mathrm{PE}$ and PA / EVOH / PE maintained the quality up to 8 months at $20 \pm 2{ }^{\circ} \mathrm{C}$ temperature. An essential quality determinative factor, which influenced the shelf life of potato main course in PA/PE and $\mathrm{PA} / \mathrm{EEVOH} / \mathrm{PE}$ packaging, was the increase in the total colour difference $\Delta \mathrm{E}^{*}$. It was affected by the significantly lower packaging light transmittance compared PET/ALU/PA / PP packaging material, thereby substantially reducing product quality.

\section{Acknowledgment}

This research was supported by the project co-funded by Local resources research and sustainable use Programme "Agricultural Resources for Sustainable Production of Qualitative and Healthy Foods in Latvia (AgroBioRes) (2014-2017)". Project No. 4 Sustainable use of local agricultural resources for qualitative and healthy food product development (FOOD).

\section{References}

1. Ahvendinen R. (2003) Novel Food Packaging Techniques. CRC Press Woodhead publishing limited Cambridge England, p. 590.
2. Awuah G.B., Ramaswamy H.S., Economides A. (2007) Thermal processing and quality: principles and overview. Chemical Engineering and Processing, Vol. 46 (46), p. 584-602.

3. Barbosa-Cánovas G. V., Medina-Meza I., Candoğan K., Bermúdez-Aguirre D. (2014) Advanced retorting, microwave assisted thermal sterilization (MATS), and pressure assisted thermal sterilization (PATS) to process meat products. Meat Science, Vol. 98 (3), p. 420-434.

4. Bindu J., Ravishankar C. N., Gopal T. K. S. (2012) Packaging of retort-processed seafood, meat and poultry. Advances in Meat, Poultry and Seafood Packaging, p. 333-362.

5. Birmpa A., Sfika V, Vantarakis A. (2013) Ultraviolet light and Ultrasound as non-thermal treatments for the inactivation of microorganisms in fresh ready-to-eat foods. International Journal of Food Microbiology, Vol. 167 (1), p. 96-102

6. Byun Y., Bae H. Y., Cooksey K., Whiteside S. (2010) Comparison of the quality and storage stability of salmon packaged in various retort pouches. LWT - Food Science and Technology, Vol. 43 (3), p. 551-555.

7. Calderón L. A., Iglesias L., Laca A., Herrero M. (2010) The utility of Life Cycle Assessment in the ready meal food industry. Resources. Conservation and Recycling, Vol. 54, p. 1196-1207.

8. Clark S., Warner H., Rodríguez J.J., Olivas G.I., Sepúlveda D., Bruins R., Barbosa-Cánovas G.V. (2002) Residual gas and storage conditions affect sensory quality of diced pears in flexible retortable pouches. Food Quality and Preference, Vol. 13, p.153-162.

9. Garcia-Segovia P., Andres-Bello, Martinez-Monzo J. (2007) Effect of Cooking Method on Mechanical Properties, Colour and Structure of Beef Muscle. Journal of Food Engineering, Vol 80, p 813-821.

10. Gomes C.C.B., Lemos G.F.C., Silva M.C., Hora I.M.C., Cruz A.G. (2014) Training of food handlers in a hotel: tool for promotion of the food safety. Journal of Food Safety, Vol. 34 (3), p. 218-223.

11. Hanssen J.O., Vold M., Schakenda V., Tufte P. A, Møller H., Olsen N. V., Skare J. (2015) Environmental profile, packaging intensity and food waste generation for three types of dinner meals. Journal of Cleaner Production, In Press, Available at: http://www.sciencedirect.com/science/article/pii/S095965 2615018351).

12. Kanatt S.R., Rao M.S., Chawla S.P., Sharma (2013) Effects of chitosan coating on shelf-life of ready-to-cook meat products during chilled storage. LWT-Food Science and Technology, Vol. 53, p. 321-326.

13. Mahon D., Cowan C., McCarthy M. (2006) The role of attitudes, subjective norm, perceived control and habit in the consumption of ready meals and takeaways in Great Britain. Food Quality and Preference, Vol. 17, p. 474-485.

14. Moronta J., Smaldini P. L., Docena G.H., Añón M.C. (2016) Peptides of amaranth were targeted as containing sequences with potential anti-inflammatory properties. Journal of Functional Foods, Vol. 21, p. 463-473.

15. Murcia M.A., Martínez-Tomé M., Nicolás M.C., Vera A.M. (2003) Extending the shelf-life and proximate compositions stability of ready to eat foods in vacuum or modified atmosphere packaging. Food Microbiology, Vol. 20, p. 671-679.

16. Olsen N.V., Menichelli E., Sørheim O., Næs T. (2012) Likelihood of buying healthy convenience food: An 
at-home testing procedure for ready-to-heat meals. Food Quality and Preference, Vol. 24 (1), p. 171-178.

17. Pardo G., Zufía J. (2012) Life cycle assessment of foodpreservation technologies. Journal of Cleaner Production, Vol. 28, p. 198-207.

18. Patras A., Tiwari B.K., Brunton N. P., Butler F. (2009) Modelling the effect of different sterilisation treatments on antioxidant activity and colour of carrot slices during storage. Food Chemistry, Vol. 114 (2), p. 484-491.

19. Regueiro J., Wenzl T. (2015) Development and validation of a stable-isotope dilution liquid chromatography-tandem mass spectrometry method for the determination of bisphenols in ready-made meals. Journal of Chromatography A, Vol. 1414, p. 110-121.

20. Remnant J., Adams J. (2015) The nutritional content and cost of supermarket ready-meals. Cross-sectional analysis. Appetite, Vol. 92, p. 36-42.

21. Simpsona R., Figueroaa I., Llanosa D., Teixeira A. (2007) Preliminary validation of on-line correction of process deviations without extending process time in batch retorting: Any low-acid canned foods. Food Control, Vol.18 (8), p. 983-987.

22. Smigic N., Djekic I., Martins M. L., Rocha A., Sidiropoulou N., Kalogianni E. P. (2016) The level of food safety knowledge in food establishments in three European countries. Food Control, Vol. 63, p. 187-194.

23. Stratakos A.C., Linton M., Patterson M. F., Koidis A. (2015) Effect of high-pressure processing on the shelf life, safety and organoleptic characteristics of lasagne ready meals during storage at refrigeration and abuse temperature. Innovative Food Science \& Emerging Technologies, Vol. 30, p. 1-7.

24. Suryawanshi M.V. (2008) Minimal processing and packaging studies in potato. Departament of horticulture. College of agriculture, Dharwad University of agricultural sciences, Dharwad, p. 82. 